\title{
Performance Evaluation of Hydroxyapatite Coatings Thermally Sprayed on Surgical Fixation Pins
}

\author{
Heleno R.A. ${ }^{1, a}$, Wagner N. S. ${ }^{2, b}$, J. R. T. Branco. ${ }^{3, c}$ \\ ${ }^{1 \text { e } 3}$ Rede Temática em Engenharia de Materiais, (REDEMAT), \\ Ouro Preto - MG - Brasil. \\ ${ }^{2}$ Setor de Ortopedia e Traumatologia do Hospital da Baleia, \\ Belo Horizonte - MG - Brasil. \\ aheleno.rocha.alves@terra.com.br, ${ }^{b}$ wagner_nogueira@hotmail.com, cj.r.t.branco@cetec.com.br
}

Keywords: Hydroxyapatite coatings, Thermal spray, Adherence, Scratch test, Fixation pins.

\begin{abstract}
Today, in the period of one year, in Brazil and throughout world, hundreds of thousands of surgical implants, both permanent and temporary, are carried out with a high cost for the patients, especially those of SUS - Sistema Único de Saúde. In addition, the SUS costs for treatment of infections that appear as a result of introduction of an implant into the human body create expenses about three times greater than the use of implants coated with biomaterials. Hydroxyapatite (HA) constitutes the base of one important group of biomaterials with excellent implant characteristics. Hydroxyapatite has been extensively studied, but the adherence relationship at the coating/substrate interface is not yet well understood. The coatings in this study were produced using substrates of AISI 316L stainless steel shaped as external fixation pins, with HA applied by a high energy plasma spray gun (HEP). The coating thicknesses were between $15 \mu \mathrm{m}$ and $98 \mu \mathrm{m}$. The mechanical evaluation of coating adhesion was conducted by scratch testing with progressive loads. Results show an increase of failure load with an increase in thickness. The clinical evaluation was carried out in the Trauma and Orthopedics Sector of the Baleia Hospital, and shows a significant decrease in inflammatory response in the human body.
\end{abstract}

\section{Introduction}

Biomaterials are a class of materials used in the medical treatment of the human body with the function of maintaining compatibility with human bone, organs and tissue. These materials have been in use for orthopedic purposes for many years. Additional applications include reconstructive surgery, heart valve parts, wire leads, aneurysm clips and dental uses. The ceramic materials represent a significant class of biomaterials, based on a biocompatibility with the human body. Biocompatibility means having a good interaction with living tissue, and can be divided in three types: bioinert, bioactive and biodegradable. Hydroxyapatite (HA), $\mathrm{Ca}_{10}\left(\mathrm{PO}_{4}\right)_{6}(\mathrm{OH})_{2}$, is a bioactive material with some kinds of human tissues: bone, cartilage and muscles. Another hydroxyapatite characteristic is as an osteoconductive, which means that the material has bioactive properties that promote rapid bone formation and strong biological fixation to bony tissue in short time periods. Hydroxyapatite is a synthetic compound similar to bone and tooth structures, and was therefore some of the first material investigated to produce coatings on metallic implants.

HA coatings have been in use for approximately 80 years to promote interaction between implants and bone. Many different application methods and different thicknesses produce coatings with different structures, adherence, and density. Depending upon substrate coating temperature, different coating phases may be produced. High energy plasma (HEP) is a thermal spray process considered to be the most versatile and efficient to produce HA coatings [1]. The mechanical properties of thermal spray coatings are dependent on pore and microcrack content, particle size, and the percentage and distribution of the phases that are present. HA coatings are the most promising material to be used in orthopedic and dental implants due to a very good biocompatibility and mechanical performance when used together with metallic substrates. The excellent bone connection to HA coatings, allied with good substrate mechanical properties, gives the implants 
sufficient strength for excellent performance in cases that require high structural strength to support high loads and/or applications needing rapid implant bioadhesion [1].

External fixation pins are widely used to stabilize bone fractures. However, when these implants are not coated with HA, the rejection rates are considerably higher than with a coated implant [2]. Some studies show that the extraction force is very much higher in HA coated implants [1], indicating that there exists a very strong interaction between bone and implant. This strong interaction happens because HA coatings act like an anti-corrosion barrier, inhibiting, and in some cases completely stopping the migration of metallic ions liberated from the substrate. The HA coating interacts with the physiological environment, and as calcium ion liberation occurs, the HA promotes an osteointegration process, fixing the implant with the surrounding tissue.

Hydroxyapatite is a ceramic material, and to better understand its mechanical properties when used in real medical applications, fracture mechanics must be utilized. The scratch test helps us to better understand the interface of the HA coating and the AISI 316L substrate. This study involves evaluation of adherence and wear resistance to better understand and rationalize the HA coating behavior, since as a ceramic material these properties are not well understood [3].

The scratch test is a technique developed some 50 years ago, and has been subsequently improved. It has been used to evaluate the adhesion of thin film coatings, especially 1 to 4 micron PVD and CVD films. The scratch test is now widely used to give qualitative information about the adhesion of thin films to substrates [4]. In this test, a diamond stylus is drawn across the HA coating surface under an increasing normal load until the coating becomes detached or fractured at some critical load "L". However, the relationship between this critical load and the adhesive strength of the interface between the substrate and coating is as yet unclear, and the adhesion is usually expressed in terms of the critical load "L". This test is relatively simple, has a low cost, and does not require any special sample preparation. These factors have provided the incentive for studies to evaluate the possibility of using the scratch test in the evaluation of thick ceramic and polymeric coatings produced by thermal spray process [5, 6 and 7].

\section{Materials and Methodology.}

The surface to be coated was prepared with a $350 \mu \mathrm{m} \mathrm{Al}_{2} \mathrm{O}_{3}$ abrasive jet (Figure. $1 b$ ) followed by chemical and ultrasonic cleaning. HA coating was produced by high energy atmospheric plasma spray (Table 1), and the HA powder was Osteosynt ${ }^{\circledR}$. The external fixation pins were AISI $316 \mathrm{~L}$ stainless steel produced by EINCO Biomaterials ${ }^{\circledR}$ with $200 \mathrm{~mm}$ length, and diameters of $3.5 \mathrm{~mm}, 5.0 \mathrm{~mm}$ and $6.0 \mathrm{~mm}$. The external fixation pins were coated with HA whose thickness varied between $15 \mu \mathrm{m}$ to $98 \mu \mathrm{m}$.

Scratch test data allied to optical microscopy and EDS analyses were the tools utilized to evaluate HA coating adherence in this work. The coating adherence was evaluated using the CSM REVETEST $^{\circledR}$ equipment using a progressive load; test parameters are shown in Table 2.

Table 1

\begin{tabular}{|l|l|}
\hline \multicolumn{2}{|c|}{ Thermal Spray Parameters } \\
\hline Argon Pressure & $100 \mathrm{PSI}$ \\
\hline Pressure Hydrogen & $50 \mathrm{PSI}$ \\
\hline Argon Flux & $100 \mathrm{SCFH}$ \\
\hline Hydrogen flux & $10 \mathrm{SCFH}$ \\
\hline Carrier Flux & $40 \mathrm{SCFH}$ \\
\hline Carrier Pressure & $50 \mathrm{PSI}$ \\
\hline Electrical Current & $400 \mathrm{~A}$ \\
\hline Tension & $62 \mathrm{~V}$ \\
\hline Distance & $100 \mathrm{~mm}$ \\
\hline
\end{tabular}




Table 2
\begin{tabular}{|l|l|}
\hline \multicolumn{2}{|c|}{ Scratch Test Parameters } \\
\hline Load Type & Progressive \\
\hline Loading Velocity $(\mathrm{Vz})$ & $60 \mathrm{~N} / \mathrm{min}$ \\
\hline Sample Velocity $(\mathrm{Vy})$ & $6 \mathrm{~mm} / \mathrm{min}$ \\
\hline Indenter Type & Rockwell C \\
\hline
\end{tabular}

The clinical evaluation was the responsibility of EINCO Biomaterials Ltda. which delegated this task to a doctor of traumatic orthopedics and Mr. Wagner Nogueira da Silva responsible for the traumatic and orthopedics section in the Baleia Hospital. The HA coated fixation pins can be seen in figure 1c. In a four year period 184 fixation pins were implanted, 92 without coatings and 92 with HA coatings. The pins with $3.5 \mathrm{~mm}$ diameter were used in children's femur and tibia and adult's humerus. The pins with $5.0 \mathrm{~mm}$ diameter were used in adult's tibia. The pins with $6.0 \mathrm{~mm}$ diameter were used in adult's femurs. These corrective surgeries were carried out at the Baleia hospital in cooperation with SUS (Sistema Único de Saúde).

The bone fragment fixations were made using one uncoated pin and one HA coated pin in the same segment, applying the same surgical technique and utilizing the same surgeon. The presence or absence of infection, and the manual extraction force were the parameters used in the clinical evaluation of HA coatings. The manual extraction force was measured using a Gedores ${ }^{\circledR}$ $4 \mathrm{Nm}$ torque meter.

\section{Results and Discussion}

The clinical evaluation observed that three HA coated fixation pins produced infections, while 28 uncoated fixation pins produced infections. The surgeon observed that the manual extraction force was easier in uncoated fixation pins. The use of the torque meter checked this observation, and the manual extraction force was approximately 10 times higher in HA coated pins.

A histological analysis shows evidence that new bone formation was more intense at the HA coated pin/bone interface. No coating failures in either the fixation or the extraction of HA coated pins were observed.

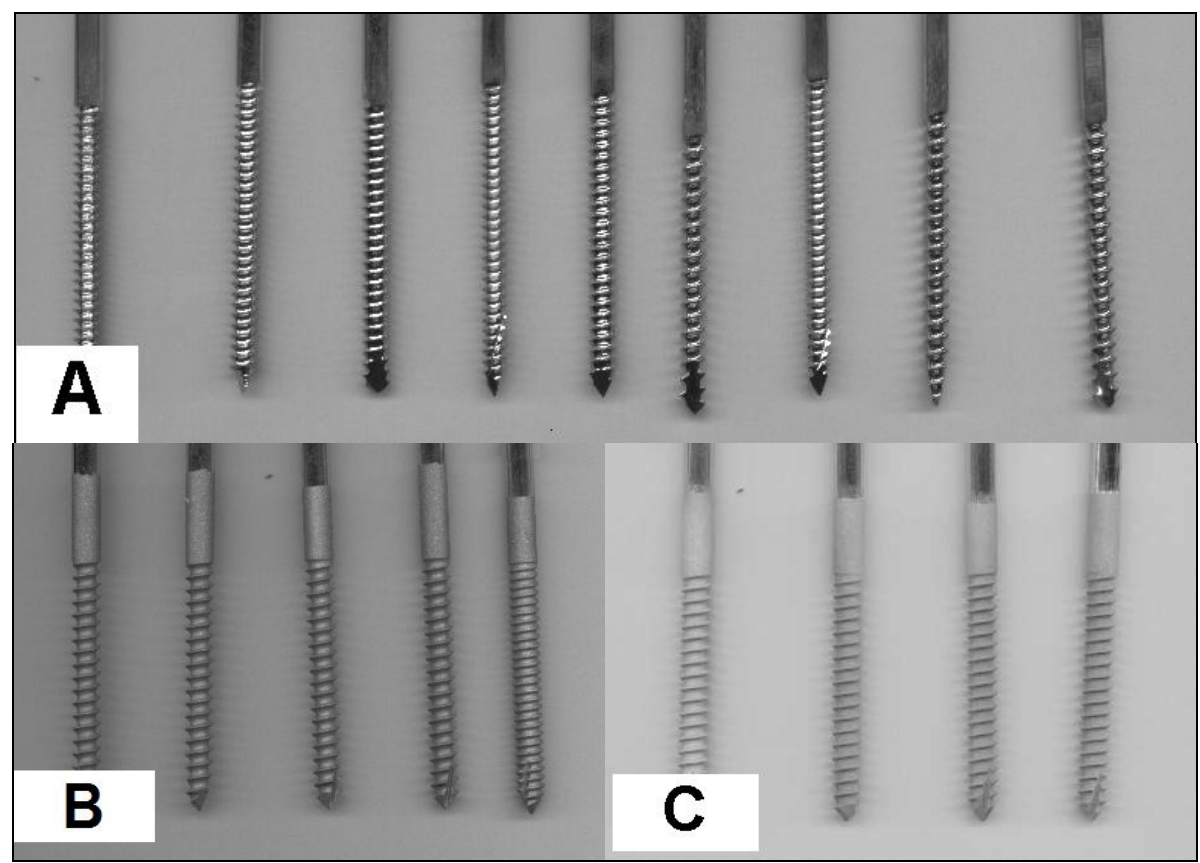

Figure 1-(a) Fixation pin tips with 50mm length and showing several thread types.

(b) Fixation pin tips with roughened surface.

(c) Fixation pin tips with plasma sprayed HA coating. 
The scratch test results show that the critical load for failure increases as the coating thickness increases. We attempted to use heat treatment after coating, but the pins' appearance shows that this is not possible with this substrate material. AISI $316 \mathrm{~L}$ stainless steels are severely affected by post-coating heat treatment for $15 \mathrm{~min}$. at $700^{\circ} \mathrm{C}$. Comparing planar sample results, we note that critical loads are approximately $80 \mathrm{~N},[8,9]$, which is very close to our results of $75 \mathrm{~N}$.

The graph 1 below shows the REVETES ${ }^{\circledR}$ data acquisition, monitoring normal load vs. tangential load during scratch testing of HA coated fixation pins with $83 \mu \mathrm{m}$ coating thickness. Figure 2 shows a correlation between the acquired data and the observed failures. There is no apparent indication of coating failure in the graphical data, although coating failure is obvious in the photograph of figure 2. It was observed that coating adhesion failure happens outside of the scratch where the HA coating was under compressive loading by the indenter.

The white area observed at the left side of figure 2, just where the scratch test begins, is a result of a Hertzian process which happens ahead of the indenter as it begins to move. This observation tends to reinforce what we postulated in other publications (Alves 2004)[8][9]; when the indenter moves during the test, it creates a tension field at the coating/substrate interface generating an adhesive failure which is clear in our case because the samples are cylindrical. In planar samples cracking occurs, but coating delamination does not occur because of the constraining effect of the surrounding coating [8,9]. Others studies [10] proposed that data from tangential force measurements do not contribute anything to elucidate the test results. They suggest that data from acoustic emissions are more useful, but in this work, in spite of changing all REVETEST $^{\circledR}$ parameters, the acoustic emissions data go completely off scale at the start of the test.

The EDS analyses shown in figure 3 are at the beginning of the failed region in the scratch test. We observe there is no damaged coating in the middle of the test region as in figure 2. The damaged coating was removed by vibrations during EDS preparation, as the sample needs to be cut for MEV observation. This demonstrates that the damaged coating has indeed lost adhesion under the indenter.

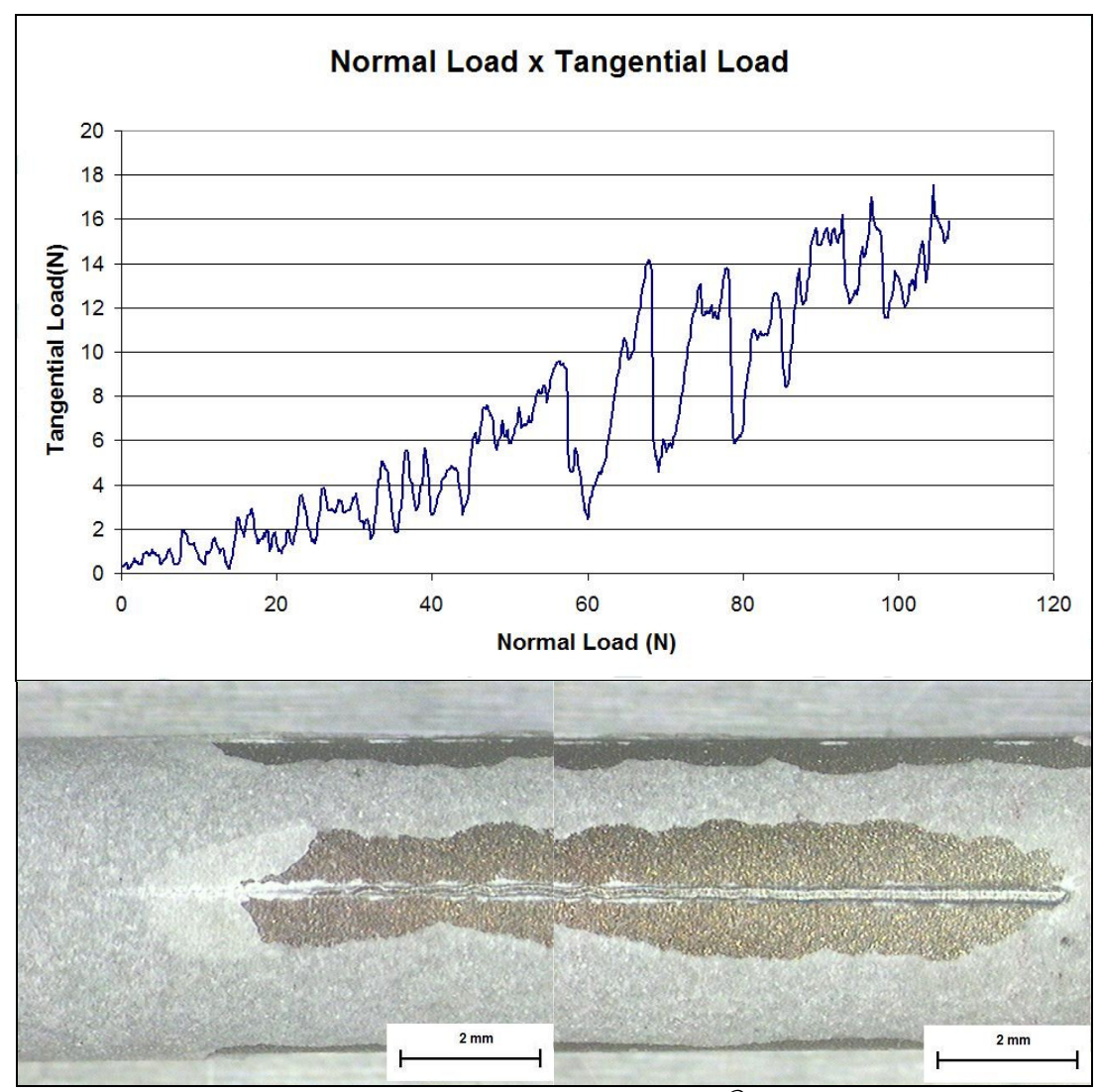

Graph 1 - shows an example of REVETEST ${ }^{\circledR}$ data from fixation pin

with coating thickness $83 \mu \mathrm{m}$ and $4,5 \mathrm{~mm}$ pin diameter.

Figure 2 - shows correlation with scratch test results. 
Figure $3 c$ shows Fe results by EDS analysis in the white, triangular region. Figures $3 b$ and $3 d$ respectively, show EDS results for calcium and phosphorous, proving that the white region in figure $3 a$ is the HA coating.

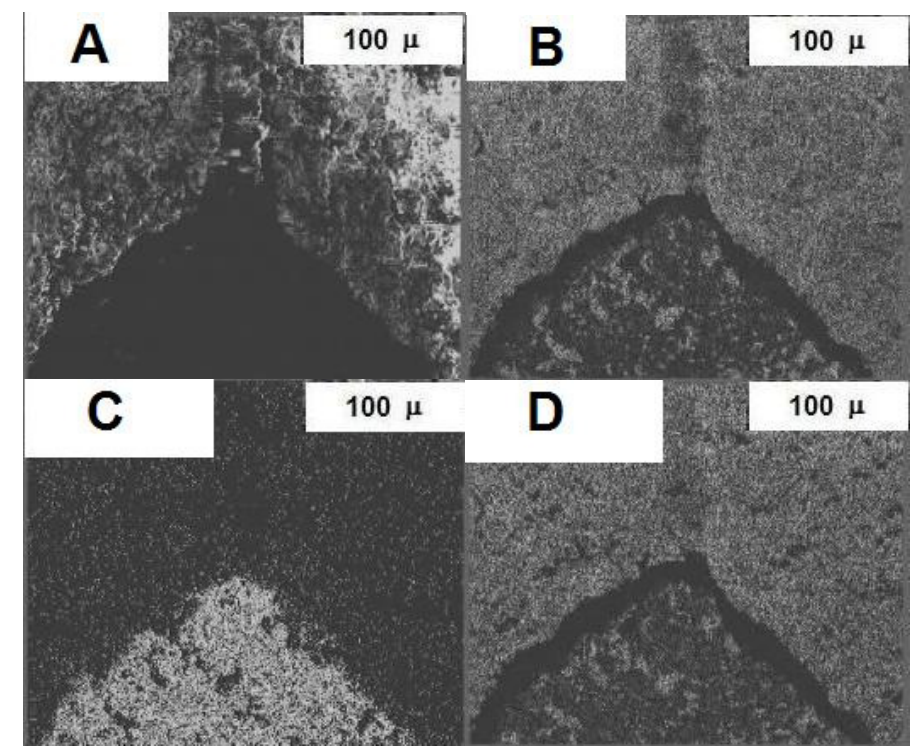

Figure 3. - MEV image showing white region from figure 2.

(a) EDS analyzed region. (b) Results for Ca presence.

(c) Results for Fe presence. (d) Results for P presence.

Graph 2 shows the critical load versus coating thickness from the scratch test results. Note the increase of critical load as coating thickness increases in all situations except two specific diameters that had a post coating thermal treatment. This post coating thermal treatment was abandoned because of negative effects on the AISI $316 \mathrm{~L}$ substrates, and is shown for comparison only. Measuring adherence in thick coatings using a scratch test is unusual because adherence is basically defined as the state when two surfaces are held together by interfacial forces such as Van der Walls force, interlocking, and chemical affinities.

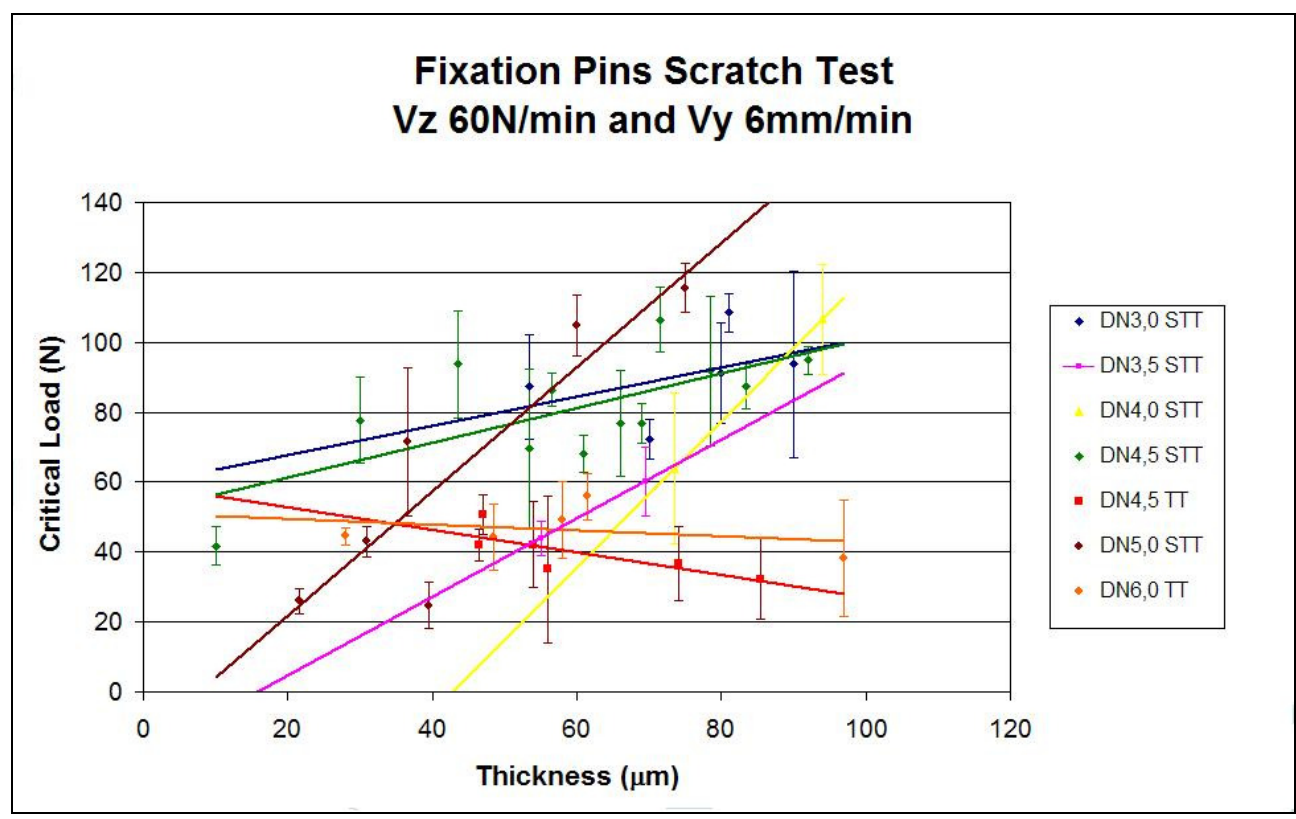

Graph2 - Scratch test results showing normal load versus thickness The red and orange lines are coatings with post-coating thermal treatment.

$V z=60 \mathrm{~N} / \mathrm{min}$ and $V y=6 \mathrm{~mm} / \mathrm{mim}$ at progressive load $D N=$ Nominal diameter of fixations pin. 
When the tribological mechanisms in a thick coating are analyzed, we must consider the fact that in this situation the coating stiffness is sufficiently high that deformation of the underlying substrate is not sufficient to cause coating cracking or delamination at low loads. These effects occur at higher loads with thicker coatings, where substrate deformation becomes an important factor [11]. The stress field under the indenter thus does not significantly affect the coating/substrate interface at low loads. In this work, we are using the practical adherence [12], and to explain the increase in critical load with thickness we have defined these coatings as " $n$ " layers, and consequently to cause the coating failure we need to cross all of these layers. In this way, when we observe the indenter move parallel to the interface it causes " $n$ " cohesive failures in the coating, but at the same time the indenter compresses the material underneath it. When the stress field induced by the indenter arrives at the substrate interface, it produces a shear stress at this interface, as we can see in figure 2, provoking adhesive coating failures that in some cases, such as planar samples, cannot be observed on the surface coating $[8,13]$

\section{Conclusions}

Scratch testing can be used to evaluate adherence in thick thermal spray coatings, although care must be taken in the choice and adjustment of the test parameters. In our case a load velocity $(\mathrm{Vz})$ equal to $60 \mathrm{~N} / \mathrm{min}$. and a sample velocity of $6 \mathrm{~mm} / \mathrm{min}$. provide a condition where a nominal $10 \mathrm{~N}$ normal load is applied for each $1 \mathrm{~mm}$ of sample dislocation. In our experiments the samples were cylindrical, so a form of residual tension takes place to help adhesive failure occur.

The clinical evaluation shows, as was expected, a very good HA thermal spray coating biocompatibility with human tissue such as bone and muscle. An inflammatory reaction occurred in only $3 \%$ of HA coated fixation pins. $30 \%$ of non-coated fixation pins produced an inflammatory reaction. A manual extractive force 10 times greater in HA coating pins shortly after surgery indicates that there is better integration between bone and HA coating than is the case with noncoated pins. This improves positive outcomes for patients because the integration between bone and HA coating gives more fracture stability without compromising posterior extraction.

\section{Acknowledgments}

REDEMAT (Rede Temática em Engenharia de Materiais), Einco Biomaterials Ltda., the Baleia Hospital's Trauma and Orthopedic Sector, Tribology and Metallographic Laboratory from CETECMG (Fundação Centro Tecnológico de Minas Gerais).

\section{References}

1. Hench, L.L., Wilson, J., "Surface Active Biomaterials", Science, 226, 630 - 636, (1984)

2. Moroni A. at all, "A Clinical Study on Hydroxyapatite Coated Fixation Pins" Bioceramics, Vol. II, $617-620$, (1984).

3. Willmann G. "Coating of implants with hydroxyapatite material connections between bone and metal". Advanced Engineering Materials, Vol 2, (1999).

4. Bull, S.J., Rickerby, D.S., Matthews, a, Leyland, A., and Pace, A.R, "The use of scratch adhesion testing for the determination of interfacial adhesion: The importance of frictional drag". Surf. Coat. Technol. 36, 503 - 517, (1988).

5. Brian J. Briscoe, Paul D. Evans and Enrico Pelillo, "Scratching Maps for Polymers". Wear 200, 137 - 147, (1996).

6. Bull, S. J., "Failure mode maps in the thin film scratch adhesion test", Tribology, (1988).

7. Veloso G., Alves H. R. and Branco J. R. T. "Effects of Isothermal Treatment on Microstructure and Scratch Test Behavior of Plasma Sprayed Zircônia Coatings".Materials Research. Vol. 7, No. 1, (2004). 
8. Alves H. R. at all. "Avaliação Tribológica de Recobrimentos de BiomateriaisProduzidos por Aspersão Térmica a Plasma atmosférico". XVI CEBCIMAT. International, Vol. 30, 491 - 498, (2004).

9. Kahlman , L., Axén, N. and Hutchings, I. M., "Correlations between tangential force and damage mechanisms in the scratch testing of ceramics", Tribology International Vol. 30, 467 414, (1997).

10. Xie, Y. and Hawthorne, H. M., "On the Possibility of Evaluation the Resistanceof Materials to Wear by Ploughing Using a Scratch Method”, Wear Vol 240, 63 - 71, (2000).

11. Holmberg, K. and Matthews, A., "Coatings Tribology Properties, Techniques and Applications in Surface Engineering”, Tribology series 28, Elsevier, Amsterdam London New York Tokyo, (1994).

12. Veloso G. "Adesão de Recobrimentos para Barreira Térmica de $\mathrm{ZrO}_{2}-\mathrm{CaO}$ Tratados Termicamente a 773 K, ao ar" Dissertação de mestrado REDEMAT (2003).

13. Fernandez-Pradas, J.M., at all, "Characterization of calcium phosphate coatings deposited by Nd: YAG laser ablation at 355nm: influence of thickness", Biomaterials Vol. 23, 1989 - 1994, (2002). 